\title{
Meniscectomy-a review of 249 cases (1963-68)
}

\author{
L. C. L. Gonet \\ F.R.C.S. \\ Consultant Orthopaedic Surgeon, \\ Putney Hospital, (Westminster Hospital \\ Teaching Group), London, S.W.15 \\ and Chelsea and Kensington Group
}

\section{Summary}

A series of 249 meniscectomies is reviewed. The average time to return to work after operation was 37 days. Statistical data are provided, and observations are made on the changing epidemiology.

\section{Introduction}

There are four published series of meniscectomies in the recent world literature. The latest comprehensive review in England was that of Wynn Parry, Nichols \& Lewis (1958) who investigated a peacetime series of 1723 airmen from Royal Air Force rehabilitation centres. The figures published by Smillie (1970) in the latest edition of his monograph now exceed 8000 meniscectomies and are unrivalled as an example of prospective research. Monographs by De Palma (1954) and Helfet (1963) provide useful comparative figures.

However, the epidemiology of meniscus lesions is changing constantly, both by country and by region. Consequently we felt that a retrospective review of our meniscectomies would be helpful:

(a) to present statistical data pertaining to one geographical location;

(b) as a simple project, to encourage research in three small Regional Board hospitals.

\section{Material}

The case-material reviewed represents the practice of three small acute general hospitals in south-west London. They serve a population of 250,000 , which is largely working-class. Because the area is largely residential, there is little heavy industry. There are a multiplicity of light engineering concerns, and a large number of sporting clubs and organizations.

Operations were performed in two of the three hospitals. Three hundred and fourteen meniscectomies were performed between 1963 and 1968 inclusive. Two hundred and forty-nine of these were performed for actual or suspected meniscus pathology, and in a further sixty-five meniscectomy was

\author{
G. E. T. RAINE \\ F.R.C.S. \\ Senior Orthopaedic Registrar, \\ St George's Hospital, London, S.W.1 \\ and S.W. Metropolitan Regional Hospital Board
}

incidental to procedures such as synovectomy or debridement. These sixty-five cases will not be discussed further.

\section{Management}

Cases were admitted under the care of the senior author, who performed the majority of the operations. A horizontal incision along the joint line was employed for choice, but oblique and vertical incisions were employed when arthrotomy an\& inspection of the joint was necessary. Postoperativelys a pressure bandage was applied by the surgeon, an $\$$ this was left undisturbed for 10 days in uncomplicated cases.

Patients were allowed up non-weightbearing on the day following operation. On the tenth day the bandage and sutures were removed and the patient discharged, taking weight on the leg, and continuing to attend the Physiotherapy Department, as an out-patient.

\section{Findings \\ Incidence}

There were 181 males and sixty-three females. Five patients had more than one operation, bringing the total to 249 . The sex-ratio $(3: 1)$ shows a higher proportion of females than Smillie (1970) in which males predominate by $5: 1$, and Jackson (1968) $8: 1$.

The incidence over 6 years is approximately $1 / 1000$ of the local population. The youngest patient was aged 12 , the oldest 71 ; the average age was 36.3 years, which compares with 41.3 years in the latter part of Smillie's series. The right knee was affected 131 times and the left knee 118 times. One hundred and eighty-two medial meniscectomies were performed, and sixty-seven lateral meniscectomies, a ratio of 2.7 to 1 . Comparable figures from other published series are given in Table 1.

Medial meniscectomy

In 133 out of 182 cases a torn meniscus was 
TABLE 1. Ratio of medial to lateral meniscectomy

\begin{tabular}{lcc}
\hline Author & $\begin{array}{c}\text { Total no. of } \\
\text { operations }\end{array}$ & $\begin{array}{c}\text { Ratio of medial } \\
\text { to lateral meniscectomies }\end{array}$ \\
\hline De Palma (1954) & 507 & $1 \cdot 6: 1$ \\
Wynn Parry et al. (1958) & 1723 & $2: 1$ \\
Smillie (1970) & 8000 & $2 \cdot 5: 1$ \\
Gonet \& Raine (this series) & 249 & $2 \cdot 7: 1$ \\
Jackson (1968) & 516 & $3 \cdot 7: 1$ \\
\hline
\end{tabular}

TABLE 2. Findings at medial meniscectomy

\begin{tabular}{|c|c|c|c|}
\hline & Male & Female & Total \\
\hline \multicolumn{4}{|l|}{ Medial } \\
\hline (a) Torn medial meniscus & 111 & 22 & 133 \\
\hline (b) Torn medial meniscus with & & & \\
\hline $\begin{array}{l}\text { cruciate ligament tear } \\
\text { (c) Torn medial meniscus with }\end{array}$ & 7 & 1 & 8 \\
\hline tear in collateral ligament & 4 & 2 & 6 \\
\hline (d) Torn medial meniscus in association & & & \\
\hline $\begin{array}{l}\text { with cyst of meniscus } \\
\text { (e) Intact meniscus including } 4\end{array}$ & 2 & 1 & 3 \\
\hline intra-meniscal cysts but no & 7 & 0 & \\
\hline \multicolumn{3}{|l|}{ (f) Intact meniscus though not } & 4 \\
\hline necessarily normal & 21 & 7 & 28 \\
\hline Total & 147 & 35 & 182 \\
\hline
\end{tabular}

excised (see Table 2). In $4 \%$ of the cases a cyst of the meniscus was present, with or without a tear of the cartilage. Associated ligamentous injuries were found in $8 \%$.

\section{Nature of the tear}

The nature of the tear of the medial meniscus was recorded on 133 occasions (Table 3).

From Table 3 it will be seen that bucket-handle

TABLE 3. Location of tear of medial meniscus (Table 2, groups a-d)

\begin{tabular}{lr}
\hline Anterior horn tear & 16 \\
Posterior horn tear & 20 \\
Central tear & 26 \\
Bucket-handle tear & 56 \\
Degenerate meniscus & 15 \\
Unspecified & 17 \\
Total & 150 \\
\hline
\end{tabular}

(bow-string) tears account for more than one-third of the torn medial menisci, and that injuries of the anterior horn are less common than those of the posterior horn.

\section{Lateral meniscectomy}

A breakdown of the figures is given in Table 4.

The striking feature of this group of cases is the presence of cysts of the lateral meniscus in over half of them. This observation is discussed in a separate paper (Raine \& Gonet, 1972). Cysts may predispose to a meniscal tear, or may be a consequence of injury.

\section{Causes of meniscus injury}

In $52 \%$ the original injury could be attributed to Association and Rugby football. The other sport mentioned by patients was judo $(4 \%)$.

TABLE 4. Findings at lateral meniscectomy

\begin{tabular}{lccr}
\hline & Male & Female & Total \\
\hline $\begin{array}{l}\text { Torn lateral meniscus } \\
\text { Torn lateral meniscus accompanied } \\
\quad \text { by cyst of meniscus }\end{array}$ & 11 & 4 & 15 \\
$\begin{array}{l}\text { Intact lateral meniscus } \\
\quad \text { accompanied by cyst of meniscus }\end{array}$ & 4 & 7 & 11 \\
$\begin{array}{l}\text { Intact lateral meniscus excised } \\
\text { (not necessarily normal) }\end{array}$ & 15 & 17 & 32 \\
Total & 6 & 3 & 9 \\
\hline
\end{tabular}


TABle 5. Circumstances of meniscus injury

\begin{tabular}{lr}
\hline Football & $52 \%$ \\
Judo & $4 \%$ \\
Road traffic accident & $3 \%$ \\
Twist injury-bending, & \\
$\quad$ kneeling or twisting in bed & $20 \%$ \\
No history of injury & $21 \%$ \\
\hline
\end{tabular}

\section{Diagnostic error}

The diagnostic error in this series amounted to $14 \%$, which compares favourably with Henderson's (1934) $18 \%$ and Dunn's (1931) $15 \%$. It is much higher than Smillie's (1970) $4 \%$ and Wynn Parry's (1958) $6 \cdot 2 \%$. In our study, nine men and two women aged between 45 and 55 years of age were cured of their symptoms and signs even though the meniscus looked macroscopically normal at removal. Some of these no doubt had undetected horizontal cleavage lesions of the posterior horn of the meniscus, or an 'immobile meniscus' (Simonds, 1964).

If we exclude these eleven, the diagnostic error would fall to $10 \%$. This figure is still too high and is a reminder to avoid complacency.

\section{Osteoarthritis}

A 5-year follow-up has been conducted on the earliest patients in the series. No evidence of osteoarthritis has been found as a consequence of meniscectomy, although we found further deterioration in knees which were already the site of osteoarthritic changes on X-ray before operation.

\section{Complications}

The commonest complication was recurrent effusion, managed by rest or physiotherapy, as appropriate.

There were eight cases of frank sepsis, fortunately controlled by antibiotic therapy, aspiration, and splintage. Three cases required re-suture of the joint capsule. This incidence of $3 \%$ is startling. It is not possible to point to any particular cause but these are thought to have been due to theatre infection. One of the operating theatres has since been closed. Two cases of deep vein thrombosis required anticoagulant therapy.

\section{Treatment days}

The average number of days between operation and discharge from all hospital and out-patient attendances in this series was 37. The two cases of deep vein thrombosis pushed up the average considerably, taking 105 and 115 days respectively, although the knees themselves were satisfactory much earlier than this.

Nevertheless, this figure of $\mathbf{3 7}$ days compares very favourably with that of Wynn Parry et al. (1958) who quoted a figure of 62 days to return servicemen to full duties.

In this study those quickest to return to work were those patients who had a bucket-handle tear excised within a short period of the original injury.

\section{Discussion}

This study reflects the current pattern of patients coming to meniscectomy in our area. Compared with other series, we have a greater proportion of women, a greater proportion of medial meniscectomies, and a large number of cysts of the lateral meniscus.

We believe that the trends towards female equality and emancipation contribute to our increased incidence in females.

On the one hand, we have no heavy industries. Smillie (1970) and Sharrard (1965) have drawn attention to the high incidence of meniscus lesions in coal-miners. This reduces our incidence in males.

On the other hand, more women are going out to work every year, and they take part in outdoor sports. More female knees are at risk and the incidence of torn menisci has increased, with a preponderance on the medial side.

Cysts of the lateral meniscus are discussed by Raine \& Gonet (1972).

\section{Acknowledgments}

We wish to thank the South-West Metropolitan Regionaf Hospital Board Decentralized Research Committee for $\vec{a}$ grant towards this review study. We thank the clerical and physiotherapy staffs of Battersea General Hospital and Putney Hospital, and B. N. Misra, Esq., F.R.C.s. for initiating this review whilst he was Resident Surgical Officer at Battersea General Hospital.

One of us (L. C. L. G.) wishes to acknowledge with gratitude the teaching of A. G. Timbrell Fisher and B. H. Burns.

\section{References}

De Palma, A.F. (1954) Diseases of the Knee, 3rd edn. Lippincott, Philadelphia.

DUNN, Naughton (1931) Diagnosis and treatment of common injuries of the knee joint. British Medical Journal, 2, 639.

HeLfeT, A.J. (1963) The Management of Internal Derangements of the Knee, Chap. 3-6. Pitman Medical Publications, London and Philadelphia.

HENDERSON, M.S. (1934) Intrinsic derangements of the knee joint. Proceedings of the Staff Meetings of the Mayo Clinic, 9, 65.

JACKSON, J.P. (1968) Degenerative changes in the knee after meniscectomy. British Medical Journal, 2, 525.

RAINE, G.E.T. \& GONET, L.C.L. (1972) Cysts of the menisc of the knee. Postgraduate Medical Journal, 48, 36.

Sharrard, W.J.W. (1965) Pressure affects on the knee in kneeling miners. Annals of the Royal College of Surgeons, 36, 309.

Simmonds, F.A.(1964) The immobile meniscus. Postgraduate Medical Journal, 40, 527.

SmILlIE, I.S. (1970) Injuries of the Knee Joint, 4th edn, Chap. 4-6. Livingstone, Edinburgh and London.

Wynn Parry, C.B., Nichols, P.J.R. \& Lewis, N.R. (1958) Meniscectomy: a review of 1723 cases. Annals of Physical Medicine, 4, 201. 